\section{(6) OPEN ACCESS}

\title{
Synovial features of patients with rheumatoid arthritis and psoriatic arthritis in clinical and ultrasound remission differ under anti-TNF therapy: a clue to interpret different chances of relapse after clinical remission?
}

\author{
Stefano Alivernini, ${ }^{1}$ Barbara Tolusso, ${ }^{1}$ Luca Petricca, ${ }^{1}$ Laura Bui, ${ }^{2}$ Gabriele Di Sante, ${ }^{1}$ \\ Giusy Peluso, ${ }^{1}$ Roberta Benvenuto, ${ }^{2}$ Anna Laura Fedele, ${ }^{1}$ Franco Federico, ${ }^{2}$ \\ Gianfranco Ferraccioli, ${ }^{1}$ Elisa Gremese ${ }^{1}$
}

Handling editor Tore K Kvien

- Additional material is published online only. To view please visit the journal online (http://dx.doi.org/10.1136/ annrheumdis-2016-210424)

IInstitute of Rheumatology, Fondazione Policlinico Universitario Agostino Gemelli, Catholic University of the Sacred Heart, Rome, Italy ${ }^{2}$ Institute of Pathology, Fondazione Policlinico Universitario Agostino Gemelli, Catholic University of the Sacred Heart, Rome, Italy

Correspondence to Professor Gianfranco Ferraccioli, Professor of Rheumatology, Institute of Rheumatology, Fondazione Policlinico Universitario A. GemelliCatholic University of the Sacred Heart, Via Giuseppe Moscati, 31 , Rome 00168, Italy: gianfranco.ferraccioli@unicatt.it

Received 27 August 2016 Revised 14 December 2016 Accepted 17 December 2016 Published Online First 24 January 2017

\section{ABSTRACT}

Objective To define the synovial characteristics of patients with rheumatoid arthritis (RA) and psoriatic arthritis (PsA) in clinical and ultrasound remission achieved by combination therapy with methotrexate (MTX) and tumour necrosis factor (TNF) blockers.

Methods Patients with RA in remission $(n=25)$ (disease activity score (DAS) $<1.6$ for at least 6 months), patients with RA in low disease activity (LDA) $(n=10)$ $(1.6<$ DAS $<2.4$ for at least 6 months) and patients with PsA in remission $(n=18)$ (DAS $<1.6$ and Psoriasis Area Severity Index (PASI) $=0$ for at least 6 months) achieved by MTX+anti-TNF (adalimumab $40 \mathrm{mg}$ or etanercept $50 \mathrm{mg}$ ) with power Doppler (PDUS)-negative synovial hypertrophy underwent synovial tissue biopsy. Patients with RA with high/moderate disease naïve to treatment $(n=50)$ were included as a comparison group. Immunostaining for cluster designation (CD)68, CD21, CD20, CD3, CD31 and collagen was performed. Results PDUS-negative patients with RA in remission showed lower histological scores for synovial CD68 ${ }^{+}$, $\mathrm{CD}^{\circ} \mathrm{O}^{+}, \mathrm{CD}^{+}$cells and $\mathrm{CD} 31^{+}$vessels and collagen deposition ( $p<0.05$ for both lining and sublining) compared with PDUS-positive patients with RA with high/ moderate disease. In addition, there was no significant difference in terms of lining and sublining $\mathrm{CD}^{+} 8^{+}$, $\mathrm{CD}^{2} \mathrm{O}^{+}, \mathrm{CD}^{+}, \mathrm{CD} 1^{+}$cells and collagen comparing PDUS-negative patients with RA in remission and in LDA, respectively. On the contrary, PDUS-negative patients with PsA in remission showed higher histological scores for sublining $\operatorname{CD68}^{+}(p=0.02)$ and $\mathrm{CD}^{+}$cells $(p=0.04)$ as well as $C D 31^{+}$vessels $(p<0.001)$ than PDUS-negative patients with RA in remission.

Conclusions PDUS-negative patients with RA in remission have comparable synovial histological features than PDUS-negative patients with RA in LDA. However, patients with PsA in remission are characterised by a higher degree of residual synovial inflammation than patients with RA in remission, despite PDUS negativity under TNF inhibition.

\section{INTRODUCTION}

Stable clinical remission is the most important goal in the treatment of chronic arthritides as rheumatoid arthritis (RA) and psoriatic arthritis (PsA). However, despite apparent clinical remission, defined with composite indices, patients with RA can experience joint damage progression. ${ }^{1}$ Ultrasound assessment (US), through synovial membrane hypertrophy (SH) and power Doppler (PDUS) evaluation, identifies residual synovitis in more than $50 \%$ of patients with $\mathrm{RA}$ in remission on the basis of their disease activity score (DAS). ${ }^{1}$ It has been shown that significantly fewer PDUS-negative patients with RA in clinical remission had a flare during the 12-month follow-up period, compared with patients with RA with PDUS positivity at the time of remission. ${ }^{2}$

The use of combined clinical and PDUS criteria allows to identify patients with RA in remission, increasing the success rate of persistence of the good clinical outcome after tumour necrosis factor (TNF) inhibitor discontinuation in patients with established disease. ${ }^{3}$ The presence of $\mathrm{SH}$ seems to be a frequent finding in patients with long-standing RA with DAS-based remission, owing to the contribution of significant long-standing disease to $\mathrm{SH}$. However, data on the composition of residual synovitis in patients with RA derive mostly from histological studies enrolling patients in remission with PDUS-positive synovitis, ${ }^{4}$ and no data were produced on patients with PsA in stable clinical remission with PDUS-residual $\mathrm{SH}$ after standardised treatments. Moreover, it is still unknown if PDUSnegative patients with RA with long-standing disease in clinical remission differ from PDUS-negative patients with RA in low disease activity (LDA) reached with the same treatment regimen.

Based on this, the aims of the study were (i) to define the histological features of PDUS-negative synovial tissue of patients with RA and PsA in clinical remission through anti-TNF treatment; (ii) to dissect the correlations between US features and inflammatory (CD68, CD21, CD20 and CD3), vascular (CD31) and fibrotic (collagen) synovial parameters and (iii) to assess the possible histological differences in terms of inflammatory synovial cells comparing patients with RA in clinical remission and in LDA status with PDUS-negative SH. 


\section{PATIENTS AND METHODS}

\section{Patients recruitment}

Patients with RA $(n=25)$ fulfilling the American College of Rheumatology 2010 revised criteria for $\mathrm{RA}^{5}$ in stable clinical remission (DAS $<1.6$ for at least 6 months) or stable LDA $(n=10)(1.6<$ DAS $<2.4$ for at least 6 months), and patients with PsA $(n=18)^{6}$ in stable clinical remission $(\mathrm{DAS}<1.6$ and PASI $=0$ for at least 6 months) and stable minimal disease activity (MDA), ${ }^{7}$ were enrolled in the study. All patients were under treatment with stable dose of methotrexate in association with TNF- $\alpha$ inhibitor (adalimumab $40 \mathrm{mg} / 14$ days or etanercept $50 \mathrm{mg} /$ week, respectively). At study entry, each patient was defined as in US remission with negative PDUS despite the presence of $\mathrm{SH}$ according to the published protocol. ${ }^{3}$ A comparison group of 50 patients with RA naive to any Disease Modifying Anti-Rheumatic Drugs (DMARDs) treatment, with high/moderate disease activity with PDUS-positive SH, was included. The study protocol was approved by the local ethical committee, and all subjects provided signed informed consent.

\section{Synovial tissue biopsy and immunohistochemistry for CD68, CD21, CD20, CD3, CD31 and collagen}

All enrolled patients underwent ultrasound-guided synovial tissue biopsy of the knee following the already published proto$\mathrm{col}^{8}$ Once collected, synovial tissue specimens were fixed in $10 \%$ neutral-buffered formalin and embedded in paraffin for histology. Briefly, paraffin-embedded synovial tissue (ST) specimens were sectioned at 3-4 $\mu \mathrm{m}$. First, sections were stained for $\mathrm{H} \& \mathrm{E}$ as follows: sections were deparaffinised in xylene and rehydrated in a graded ethanol series. Then they were stained in haematoxylin and counterstained in eosin/phloxine. Finally, sections were dehydrated, cleared in xylene and mounted with Bio Mount (Bio-Optica). Other sections were stained for CD68 mouse antihuman monoclonal antibody (clone 514H12) or
CD21 mouse antihuman monoclonal antibody (clone 2G9) or CD20 mouse antihuman monoclonal antibody (clone L26) or CD3 mouse antihuman monoclonal antibody (clone LN10) or CD31 mouse antihuman monoclonal antibody (clone 1A10) (all from Leica Biosystem, Newcastle, UK) by immunostainer BOND MAX III (Leica). ${ }^{9}$

ST slides were stained for collagen using the Masson Trichrome Goldner with light green (Bio-Optica; 04-011802) as follows: slides were washed in distilled water; then six drops of Weigert's iron haematoxylin, provided by the manufacturer, were put on the sections and left to act $10 \mathrm{~min}$. Without washing, the slides were drained, and 10 drops of picric acid alcoholic stable solution were added on the sections. Then, the slides were quickly (3-4s) washed in distilled water, and 10 drops of ponceau acid fuchsin according to Masson were added on the sections and left to act $4 \mathrm{~min}$. Then, the slides were washed in distilled water, and 10 drops of phosphomolybdic acid solution were added on the sections and left to act $10 \mathrm{~min}$. Without washing, the slides were drained, and 10 drops of Light Green Solution, according to Goldner, were added and left to act $5 \mathrm{~min}$. Then, the slides were washed in distilled water and rapidly dehydrated through ascending alcohols. Reaction was done for $1 \mathrm{~min}$ in absolute alcohol. Finally, the slides were cleared in xylene and mounted.

Slides were examined by two independent evaluators using a light microscope (Leica DM 2000), and all tissues were evaluated using a numerical score based on the number of $\mathrm{CD} 8^{+}$, $\mathrm{CD} 21^{+}, \mathrm{CD} 3^{+}, \mathrm{CD} 20^{+}$and $\mathrm{CD} 31^{+}$cells in the lining and sublining areas of the section (three different fields in each section), with a score of 0 indicating no positive cells; 1 indicating $<10 \%$ positive cells; 2 indicating $10 \%-50 \%$ positive cells; and 3 indicating $>50 \%$ positive cells. ${ }^{10}$ The inter-rater agreement coefficient was assessed for each single immunohistochemistry (IHC) marker (see online supplementary table S1).

Table 1 Demographic, clinical and immunological parameters of enrolled patients with RA and PsA

\begin{tabular}{|c|c|c|c|c|c|c|c|c|}
\hline & $\begin{array}{l}\text { Remission RA } \\
\text { cohort }(n=25)\end{array}$ & $\begin{array}{l}\text { LDA RA cohort } \\
(n=10)\end{array}$ & $\begin{array}{l}\text { High/moderate RA } \\
\text { cohort }(n=50)\end{array}$ & $\begin{array}{l}\text { Remission PsA } \\
\text { cohort }(n=18)\end{array}$ & p Value* & p Value ** & p Value ${ }^{* * *}$ & $p$ Value $\wedge$ \\
\hline Age, years $($ mean $\pm S D)$ & $57.20 \pm 14.95$ & $52.00 \pm 16.38$ & $54.36 \pm 15.33$ & $56.67 \pm 16.66$ & 0.45 & 0.69 & 0.37 & 0.80 \\
\hline Gender, female (\%) & $21(84.0)$ & $6(60.0)$ & $40(80.00)$ & $11(61.1)$ & 0.68 & 0.17 & 0.13 & 0.08 \\
\hline Disease duration, years $($ mean $\pm S D)$ & $9.70 \pm 2.81$ & $9.52 \pm 3.03$ & $2.19 \pm 2.82$ & $8.50 \pm 3.01$ & $<0.001$ & $<0.001$ & 0.06 & 0.89 \\
\hline Treatment duration, years $($ mean \pm SD) & $7.01 \pm 3.41$ & $6.98 \pm 2.75$ & - & $6.83 \pm 2.95$ & - & - & 0.98 & 0.63 \\
\hline AB positivity, $n(\%)$ & $17(68.0)$ & $5(50.0)$ & $28(56.0)$ & $0(0.0)$ & 0.31 & 0.72 & 0.27 & $<0.001$ \\
\hline $\mathrm{GH}($ mean $\pm \mathrm{SD})$ & $32.00 \pm 12.73$ & $37.88 \pm 27.90$ & $55.80 \pm 23.56$ & $33.44 \pm 31.93$ & 0.001 & 0.02 & 0.37 & 0.89 \\
\hline TJC28 (mean \pm SD) & $0.04 \pm 0.20$ & $1.20 \pm 1.23$ & $7.14 \pm 6.21$ & $0.39 \pm 0.61$ & $<0.001$ & $<0.001$ & 0.01 & 0.10 \\
\hline TJC44 (mean \pm SD) & $0.16 \pm 0.47$ & $1.60 \pm 1.95$ & $8.66 \pm 8.84$ & $0.39 \pm 0.61$ & $<0.001$ & $<0.001$ & 0.02 & 0.11 \\
\hline SJC28 (mean \pm SD) & $0.12 \pm 0.33$ & $1.00 \pm 1.05$ & $7.04 \pm 6.03$ & $0.22 \pm 0.43$ & $<0.001$ & $<0.001$ & 0.02 & 0.38 \\
\hline SJC44 (mean \pm SD) & $0.16 \pm 0.37$ & $1.00 \pm 1.05$ & $8.68 \pm 8.72$ & $0.22 \pm 0.43$ & $<0.001$ & $<0.001$ & 0.02 & 0.61 \\
\hline \multicolumn{9}{|l|}{ Treatment regimen } \\
\hline MTX dose, mg/week & $14.42 \pm 3.56$ & $14.38 \pm 4.96$ & - & $14.79 \pm 3.45$ & - & - & 0.97 & 0.97 \\
\hline Etanercept 50 mg/week & $13(52.0)$ & $6(60.0)$ & - & $10(55.6)$ & - & - & 0.67 & 0.82 \\
\hline Adalimumab $40 \mathrm{mg} / 2$ weeks & $12(48.0)$ & $4(40.0)$ & - & $8(44.4)$ & - & - & 0.67 & 0.82 \\
\hline
\end{tabular}

$\mathrm{p}^{*}$ : Patients with RA in remission versus patients with RA with high/moderate disease; $\mathrm{p}^{* *}$ : Patients with RA in LDA versus patients with RA with high/moderate disease; $\mathrm{p}^{* * *}$ : Patients with RA in remission versus patients with RA in LDA; $p^{\wedge}$ : Patients with RA in remission versus patients with PsA in remission; Bold: $p<0.05$.

$A B$, autoantibody; BMI, body mass index; CRP, C reactive protein; DAS, disease activity score; ESR, erythrocyte sedimentation rate; GH, global health; LDA, low disease activity; MTX, methotrexate; PSA, psoriatic arthritis; RA, rheumatoid arthritis; SJC, swollen joint count; TJC, tender joint count. 


\section{Statistical analysis}

Statistical analysis was performed using SPSS V. 20.0 (SPSS. Chicago, Illinois, USA) and Prism software (GraphPad, San Diego, California, USA). Categorical and quantitative variables were described as frequencies, percentage and mean \pm SD. Data on demographic and clinical features were compared between patients by the non-parametric Mann-Whitney $U$ test or $\chi^{2}$ test, as appropriate. Spearman's rank correlation test was used for correlation in all analyses. A value of $\mathrm{p}<0.05$ was considered statistically significant.

\section{RESULTS}

\section{Demographic, clinical and immunological characteristics of enrolled patients}

Demographic, clinical and immunological characteristics of the enrolled patients with RA are summarised in table 1. PDUS-negative patients with RA in remission and in LDA did not differ for SH thickness in all the assessed joints (table 2) and showed significantly lower DAS and DAS28 values $(\mathrm{p}<0.001$ and $\mathrm{p}<0.001$, respectively), global health $(\mathrm{GH})$ assessment $(\mathrm{p}<0.001)$, tender joint count over 44 and 28 joints $(\mathrm{p}<0.001$ and $\mathrm{p}<0.001$, respectively) and swollen joint count over 44 and 28 joints $(\mathrm{p}<0.001$ and $\mathrm{p}<0.001$, respectively) compared with patients with RA with high/moderate disease activity. Patients with RA in clinical remission did not differ from patients with RA in LDA in terms of age, gender, disease duration and treatment duration (table 1). Using a stricter criteria to define stable clinical remission (Simplified Disease Activity Index (SDAI) $\leq 3.3$ for at least 6 months), 14/25 (56.0\%) patients with RA were considered to be in SDAI remission in our cohort despite DAS-based definition. Analysing the different parameters used for SDAI calculation, only the patient global assessment of disease activity $(\mathrm{p}<0.001)$ was the item limiting the achievement of SDAI remission in our PDUS-negative RA cohort (see online supplementary table S2).

\section{Histological features of synovial tissue do not differ in PDUS-negative patients with RA in remission compared with PDUS-negative patients with RA in LDA under TNF blockade}

All included patients underwent synovial tissue biopsy of the knee, which was assessed for the presence of resident $\mathrm{CD} 68^{+}$, $\mathrm{CD} 21^{+}, \mathrm{CD} 20^{+}$and $\mathrm{CD}^{+}$cells. In figure $1 \mathrm{~A}-\mathrm{C}$, example images of immunostaining for $\mathrm{CD}_{6} 8^{+}, \mathrm{CD} 21^{+}, \mathrm{CD} 20^{+}$and $\mathrm{CD}^{+}$cells in synovial tissue from patients with RA with high/ moderate disease, in LDA and in clinical remission, respectively are shown. In particular, PDUS-negative patients with RA in

Table 2 Parameters at US assessment of patients with RA in remission, patients with RA in LDA and patients with PsA in remission at study entry

\begin{tabular}{|c|c|c|c|c|c|}
\hline & $\begin{array}{l}\text { Remission RA } \\
\text { cohort }(n=25)\end{array}$ & $\begin{array}{l}\text { LDA RA cohort } \\
(n=10)\end{array}$ & $\begin{array}{l}\text { Remission PsA } \\
\text { cohort }(n=18)\end{array}$ & p Value* & p Value** \\
\hline \multicolumn{6}{|l|}{ Wrist } \\
\hline $\mathrm{RC}$ SH, mm (mean $\pm \mathrm{SD})$ & $1.53 \pm 0.88$ & $1.54 \pm 1.06$ & $1.31 \pm 0.61$ & 0.98 & 0.37 \\
\hline $\mathrm{RC}$ SH score $($ mean \pm SD) & $0.36 \pm 0.64$ & $0.50 \pm 0.70$ & $0.22 \pm 0.55$ & 0.57 & 0.46 \\
\hline IC SH, mm (mean \pm SD) & $2.39 \pm 1.14$ & $2.75 \pm 1.33$ & $2.74 \pm 0.54$ & 0.43 & 0.23 \\
\hline IC SH score (mean \pm SD) & $0.76 \pm 0.78$ & $1.10 \pm 0.99$ & $0.62 \pm 0.41$ & 0.29 & 0.49 \\
\hline \multicolumn{6}{|l|}{ MCP-PIP (dorsal view) } \\
\hline II MCP SH, mm (mean \pm SD) & $0.61 \pm 0.49$ & $0.65 \pm 0.77$ & $0.43 \pm 0.35$ & 0.85 & 0.19 \\
\hline II MCP SH score (mean \pm SD) & $0.50 \pm 0.51$ & $0.67 \pm 0.50$ & $0.51 \pm 0.48$ & 0.44 & 0.95 \\
\hline III MCP SH, mm (mean \pm SD) & $0.68 \pm 0.64$ & $0.69 \pm 0.94$ & $0.55 \pm 0.38$ & 0.97 & 0.45 \\
\hline III MCP SH score (mean \pm SD) & $0.75 \pm 0.53$ & $0.78 \pm 0.67$ & $0.54 \pm 0.52$ & 0.89 & 0.20 \\
\hline II PIP SH, mm (mean \pm SD) & $0.78 \pm 0.42$ & $0.74 \pm 0.27$ & $0.60 \pm 0.30$ & 0.78 & 0.13 \\
\hline II PIP SH score (mean \pm SD) & $0.38 \pm 0.67$ & $0.10 \pm 0.20$ & $0.34 \pm 0.36$ & 0.21 & 0.45 \\
\hline III PIP SH, mm (mean \pm SD) & $0.83 \pm 0.32$ & $0.75 \pm 0.29$ & $0.57 \pm 0.26$ & 0.50 & 0.10 \\
\hline III PIP SH score (mean \pm SD) & $0.22 \pm 0.43$ & $0.25 \pm 0.46$ & $0.23 \pm 0.44$ & 0.62 & 0.98 \\
\hline \multicolumn{6}{|l|}{ MCP-PIP (volar view) } \\
\hline II MCP SH, mm (mean \pm SD) & $0.45 \pm 0.53$ & $0.84 \pm 0.71$ & $0.47 \pm 0.54$ & 0.10 & 0.91 \\
\hline II MCP SH score (mean \pm SD) & $0.41 \pm 0.59$ & $0.78 \pm 0.64$ & $0.46 \pm 0.66$ & 0.11 & 0.88 \\
\hline III MCP SH, mm (mean \pm SD) & $0.43 \pm 0.47$ & $0.20 \pm 0.21$ & $0.39 \pm 0.43$ & 0.15 & 0.91 \\
\hline III MCP SH score $($ mean \pm SD) & $0.38 \pm 0.59$ & $0.25 \pm 0.46$ & $0.23 \pm 0.44$ & 0.53 & 0.60 \\
\hline II PIP SH, mm (mean \pm SD) & $0.79 \pm 0.54$ & $0.51 \pm 0.45$ & $0.63 \pm 0.36$ & 0.16 & 0.54 \\
\hline II PIP SH score (mean \pm SD) & $0.33 \pm 0.64$ & $0.23 \pm 0.35$ & $0.21 \pm 0.47$ & 0.64 & 0.80 \\
\hline III PIP SH, mm (mean \pm SD) & $0.76 \pm 0.37$ & $0.61 \pm 0.53$ & $0.57 \pm 0.38$ & 0.35 & 0.61 \\
\hline III PIP SH score (mean \pm SD) & $0.38 \pm 0.49$ & $0.33 \pm 0.50$ & $0.27 \pm 0.43$ & 0.91 & 0.56 \\
\hline \multicolumn{6}{|l|}{ Knee } \\
\hline knee $\mathrm{SH}, \mathrm{mm}(\mathrm{mean} \pm \mathrm{SD})$ & $6.50 \pm 2.91$ & $8.01 \pm 2.59$ & $5.50 \pm 2.41$ & 0.16 & 0.34 \\
\hline \multicolumn{6}{|l|}{ MTP } \\
\hline II MTP SH, mm (mean \pm SD) & $0.73 \pm 0.43$ & $0.60 \pm 0.29$ & $0.88 \pm 0.71$ & 0.39 & 0.82 \\
\hline V MTP SH, mm (mean \pm SD) & $0.30 \pm 0.34$ & $0.30 \pm 0.36$ & $0.37 \pm 0.44$ & 0.99 & 0.87 \\
\hline
\end{tabular}

$p^{*}$ : Patients with RA in remission versus patients with RA in LDA; $p^{* *}$ : Patients with RA in remission versus patients with PsA in remission.

IC, intercarpal joint; LDA, low disease activity; MCP, metacarpal-phalangeal joint; MTP, metatarsal-phalangeal joint; PIP, proximal interphalangeal joint; PsA, psoriatic arthritis; RA, rheumatoid arthritis; RC, radiocarpal joint; SH, synovial hypertrophy; US, ultrasound assessment. 
clinical remission showed lower histological scores for $\mathrm{CD}^{+} 8^{+}$ cells $\left(p<0.001\right.$ for both lining and sublining), CD $20^{+}$cells $(p<0.001$ for lining and $p=0.02$ for sublining, respectively) and $\mathrm{CD}^{+}$cells $(\mathrm{p}=0.002$ for lining and $\mathrm{p}=0.003$ for sublining) compared with patients with RA with high/moderate disease activity. PDUS-negative patients with RA in LDA showed lower histological scores for lining $(p=0.03)$ and sublining $(p=0.01)$ $\mathrm{CD}^{+} 8^{+}$cells, lining $(\mathrm{p}=0.01)$ and sublining $(\mathrm{p}=0.05) \mathrm{CD} 20^{+}$ cells $(p=0.05)$ and lining $(p=0.04)$ and sublining $(p=0.05)$ $\mathrm{CD}^{+}$cells compared with patients with RA with high/moderate disease activity (figure 1D-I). In addition, follicular structures were found in $8.0 \%$ of patients with RA in clinical remission $(\mathrm{p}<0.001), 10.0 \%$ of patients with RA in LDA $(\mathrm{p}=0.01)$ compared with $56.0 \%$ of patients with RA with high/moderate disease activity. None of the synovial follicular structures found in PDUS-negative patients with RA in clinical remission and LDA was positive for $\mathrm{CD} 21^{+}$cells compared with $71.4 \%$ of $\mathrm{CD} 21^{+}$synovial follicles in patients with $\mathrm{RA}$ with high/moderate disease activity $(\mathrm{p} \leq 0.001)$ (figure $1 \mathrm{~A}-\mathrm{C}$ ).

Moreover, PDUS-negative patients with RA in clinical remission did not differ from PDUS-negative patients with RA in LDA in terms of histological scores for $\mathrm{CD}^{+} 8^{+}$cells $(\mathrm{p}=0.39$ and $\mathrm{p}=0.28), \mathrm{CD}^{+} 0^{+}$cells $(\mathrm{p}=0.49$ and $\mathrm{p}=0.65)$ and $\mathrm{CD}^{+}$cells $(\mathrm{p}=0.92$ and $\mathrm{p}=0.29)$, respectively, in the lining and sublining areas (figure 1D-I). These findings were confirmed dividing PDUS-negative patients with RA in remission using the SDAI cut-off (see online supplementary table S2).
A
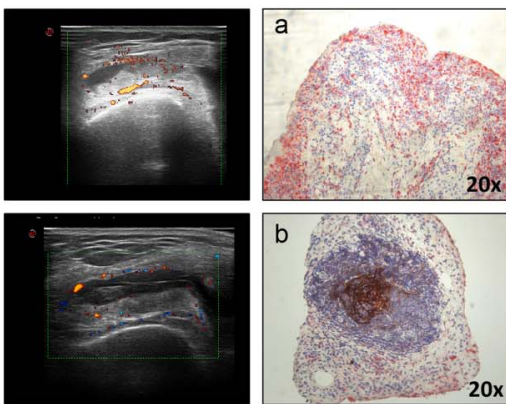

B
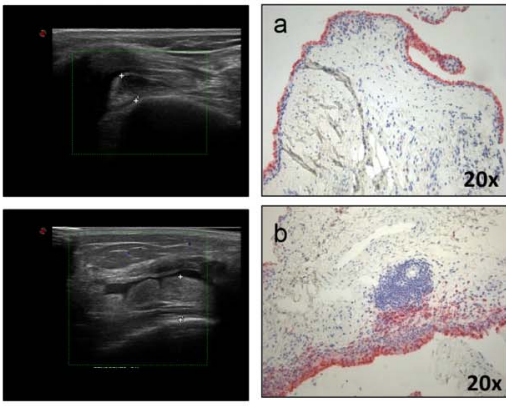

C
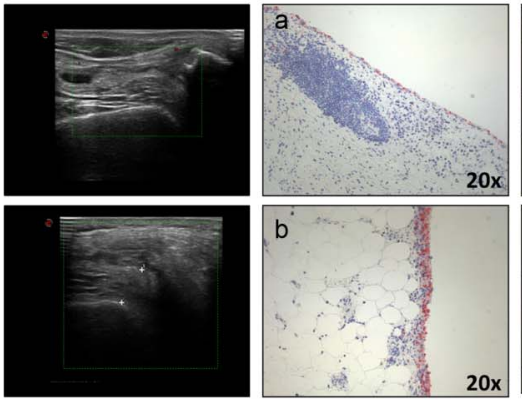
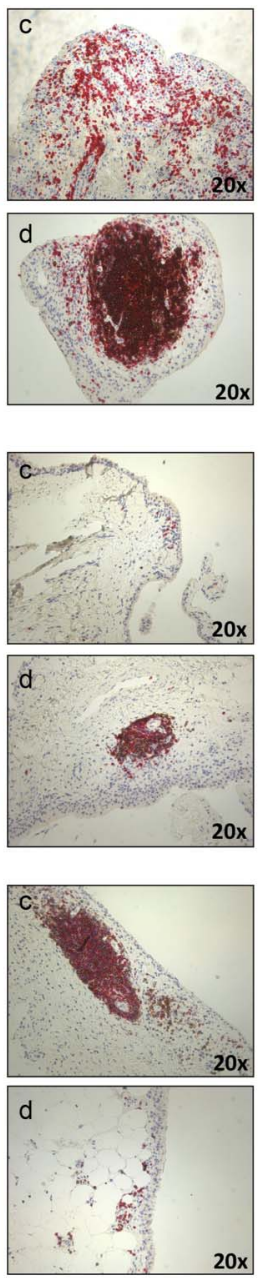

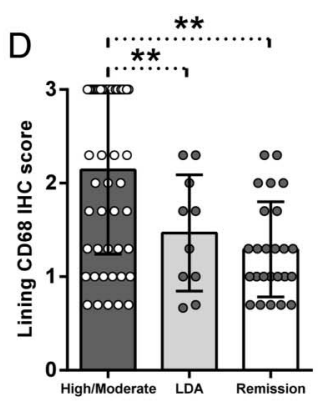

E

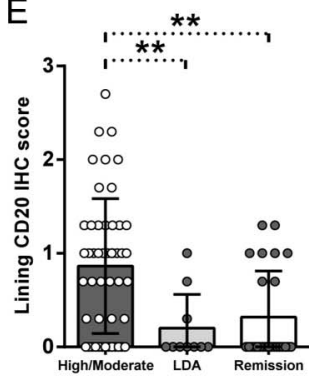

$\mathrm{F}$

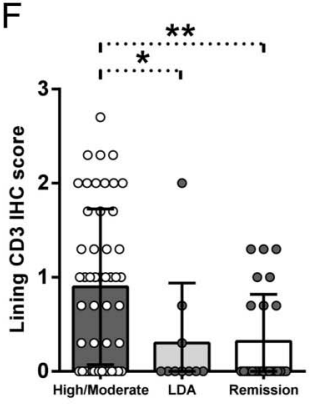

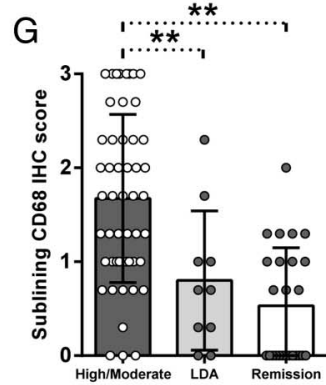
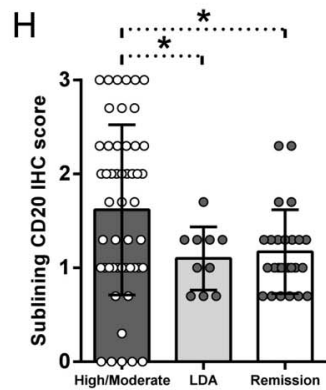

I

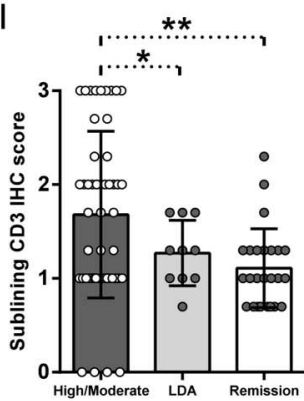

Figure 1 (A-I) IHC staining for CD68/CD21 and CD3/CD20 on ST of patients with rheumatoid arthritis (RA) in disease remission, in low disease activity (LDA) and in high/moderate disease. (A) Example photos of CD68 (red)/CD21 (brown) ( $\mathrm{A}^{\mathrm{a}, \mathrm{b}}$ ) and CD3 (red)/CD20 (brown) ( $\mathrm{A}^{\mathrm{c}, \mathrm{d}}$ ) staining of ST biopsies from patients with RA with high/moderate disease activity naïve to any DMARDs treatment (magnification 20x). (B) Example photos of CD68 (red)/CD21 (brown) ( ${ }^{\mathrm{a}, \mathrm{b}}$ ) and CD3 (red)/CD20 (brown) ( $\mathrm{B}^{\mathrm{c}, \mathrm{d}}$ ) staining of ST biopsies from patients with RA in LDA status (magnification $20 \times$ ). (C) Example photos of CD68 (red)/CD21 (brown) $\left(\mathrm{C}^{\mathrm{a}, \mathrm{b}}\right.$ ) and CD3 (red)/CD20 (brown) ( $\mathrm{C}^{\mathrm{c}, \mathrm{d}}$ ) staining of ST biopsies from patients with RA in clinical remission (magnification 20x); ultrasound assessment (US) picture with power doppler (PD) scale of the knee used for ST biopsy is shown next to the corresponding patient. (D) Lining IHC score for $\mathrm{CD} 68^{+}$cells; high/moderate versus LDA patients with RA, * $\mathrm{p}=0.03$; high/moderate versus remission patients with $R A,{ }^{* *} p<0.001$; LDA versus remission patients with $R A, p=0.39$. (E) Sublining IHC score for $C D 68^{+}$cells; high/moderate versus LDA patients with $R A,{ }^{*} p=0.01$; high/moderate versus remission patients with RA, ${ }^{* *} p<0.001$; LDA versus remission patients with RA, $p=0.28$. (F) Lining IHC score for $C D 20^{+}$cells; high/moderate versus LDA patients $R A,{ }^{*} p=0.01$; high/moderate versus remission patients with $R A$, ${ }^{* *} p<0.001$; LDA versus remission patients with RA, $p=0.49$. (G) Sublining IHC score for CD20 ${ }^{+}$cells; high/moderate versus LDA patients with RA, ${ }^{*} p=0.05$; high/moderate versus remission patients with $R A,{ }^{*} p=0.02$; LDA versus remission patients with RA, $p=0.65$. (H) Lining IHC score for CD3 ${ }^{+}$ cells; high/moderate versus LDA patients with $R A,{ }^{*} p=0.04$; high/moderate versus remission patients with RA, ** $p=0.002$; LDA versus remission patients with RA, $p=0.92$. (I) Sublining IHC score for $\mathrm{CD}^{+}$cells; high/moderate versus LDA patients with $\mathrm{RA}$, * $\mathrm{p}=0.05$; high/moderate versus remission patients with $R A,{ }^{* *} p=0.003$; LDA versus remission patients with $R A, p=0.29$. 


\section{PDUS-negative patients with RA in remission do not differ from PDUS-negative patients with RA in LDA for synovial CD31 ${ }^{+}$vessels under TNF inhibitors}

At study entry, all enrolled patients with RA in remission and in LDA were PDUS-negative, regardless of SH presence. Performing CD31 immunohistochemistry staining, both PDUS-negative patients with RA in remission (figure $2 \mathrm{C}^{\mathrm{a}}$, b) and PDUS-negative patients with RA in LDA (figure $2 \mathrm{~B}^{\mathrm{a}}$, b) showed significantly less $\mathrm{CD} 31^{+}$vessels compared with patients with RA with high/moderate disease activity (figure $\left.2 \mathrm{~A}^{\mathrm{a},} \mathrm{b}^{\mathrm{b}}\right) \quad(\mathrm{p}<0.001$ for both PDUS-negative patients with RA in remission and in LDA versus high/moderate patients with RA, respectively) (figure 2D). Moreover, PDUS-negative patients with RA in remission did not differ in terms of $\mathrm{CD} 31^{+}$vessels compared with PDUS-negative patients with RA in LDA after TNF inhibitors $(p=0.57)$ (figure 2D).

\section{PDUS-negative patients with RA in remission do not differ from PDUS-negative patients with RA in LDA for synovial collagen distribution under TNF inhibitor}

To assess the rate of inflammation resolution in patients with RA after TNF inhibition, we performed Masson Trichrome Goldner staining for collagen distribution assessment in synovial tissue. PDUS-negative patients with RA in remission (figure $3 \mathrm{C}^{\mathrm{a}, \mathrm{b}}$ ) showed significantly higher collagen deposition in the lining and sublining areas $(\mathrm{p}<0.001$ for both) compared with patients with RA with high/moderate disease activity (figure $3 \mathrm{~A}^{\mathrm{a} \text {, b }}$ ) (figure 3D-E). PDUS-negative patients with RA in LDA (figure $3 \mathrm{~B}^{\mathrm{a}}{ }^{\mathrm{b}}$ ) showed a higher extent of collagen deposition in the lining $(\mathrm{p}=0.03)$ and sublining $(\mathrm{p}<0.001)$ areas (figure $3 \mathrm{D}-\mathrm{E})$ compared with patients with RA with high/moderate disease activity (figure 3D-E). Finally, PDUS-negative patients with RA in remission did not differ in terms of collagen deposition compared with PDUS-negative patients with RA in LDA under TNF blockade $(p=0.74$ and $p=0.61$ for lining and sublining, respectively) (figure $3 \mathrm{E}-\mathrm{D}$ ).

PDUS-negative patients with $R A$ in remission have less resident synovial $\mathrm{CD}_{68}{ }^{+}, \mathrm{CD}^{+}$and $\mathrm{CD} 1^{+}$cells compared with PDUS-negative patients with PsA in remission under TNF inhibitor

To assess the possible histological differences between residual synovial inflammation in RA and other inflammatory diseases, we compared synovial distribution of $\mathrm{CD} 68^{+}, \mathrm{CD} 21^{+}, \mathrm{CD} 20^{+}$, $\mathrm{CD}^{+}$and $\mathrm{CD}^{+} 1^{+}$cells of PDUS-negative patients with RA $(n=25)$ and PDUS-negative patients with PsA $(n=18)$ in stable clinical remission under TNF blockade. As shown in table 1, there were no significant differences between PDUS-negative patients with RA and PsA in remission according to demographic, clinical and inflammatory parameters (erythrocyte sedimentation rate (ESR) and $C$ reactive protein (CRP)) (table 1). Moreover, PDUS-negative patients with RA and PsA did not differ according to the $\mathrm{SH}$ thickness in all the assessed joints (table 2).

As shown in figure 4A, B, despite similar US characteristics at the time of study entry, PDUS-negative patients with PsA in remission showed significantly higher degree of residual synovitis compared with PDUS-negative patients with RA in remission in terms of $\mathrm{CD}_{6} 8^{+}, \mathrm{CD}^{+}$and $\mathrm{CD} 31^{+}$cells distribution. In particular, PDUS-negative patients with PsA in remission

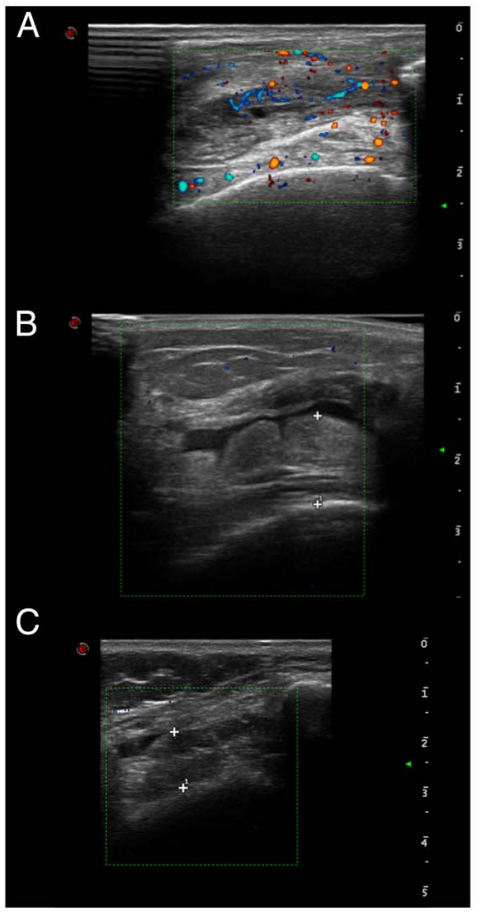

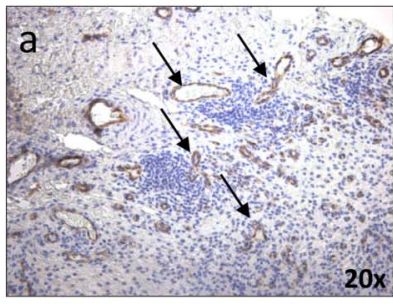
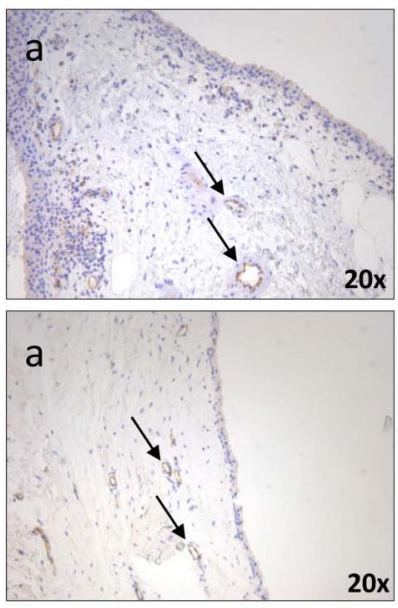
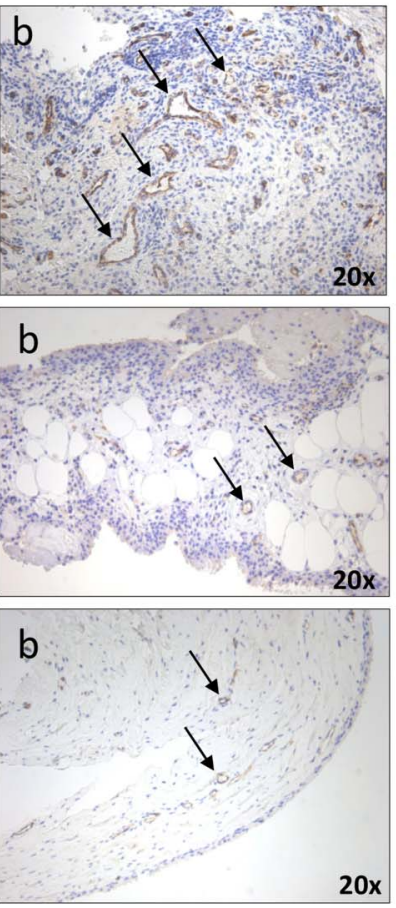

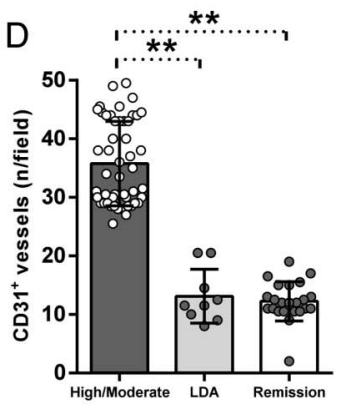

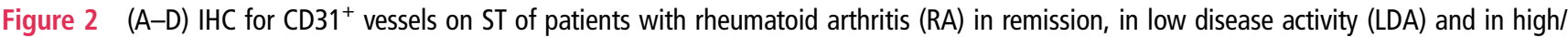
moderate disease. (A) Example photos of CD31 (brown) staining of ST from patient with high/moderate RA (a, b) (magnification 20x); corresponding ultrasound assessment (US) picture with PD scale (PD score=2) of the knee used for ST biopsy is shown. (B) Example photos of CD31 (brown) staining of ST from patient with RA in LDA $(a, b)$ (magnification 20x); corresponding US picture with PD scale (PD score $=0)$ of the knee used for ST biopsy is shown. (C) Example photos of CD31 (brown) staining of ST from patient with RA in remission (a, b) (magnification 20x); corresponding US picture with PD scale (PD score=0) of the knee used for ST biopsy is shown. (D) IHC score for CD31 ${ }^{+}$vessels in ST of enrolled cohorts; high/ moderate versus LDA in patients with $R A,{ }^{* *} p<0.001$; high/moderate versus remission in patients with $R A,{ }^{*} p<0.001$; LDA versus remission in patients with $R A, p=0.57$. 

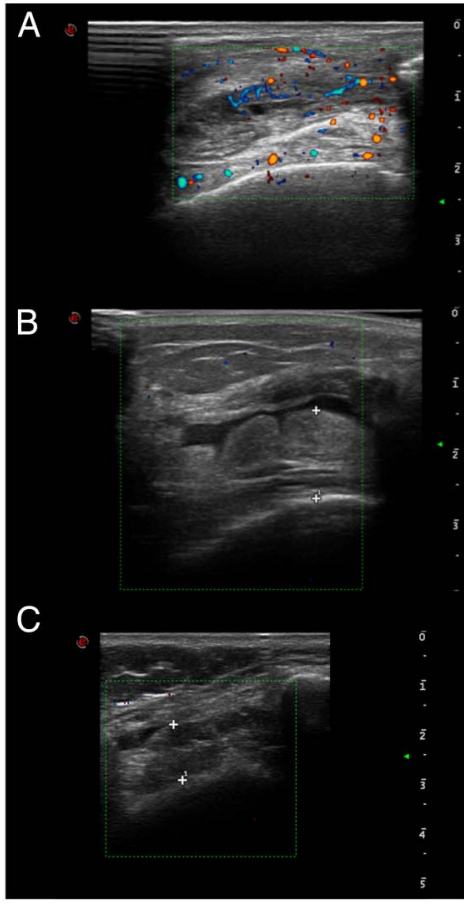
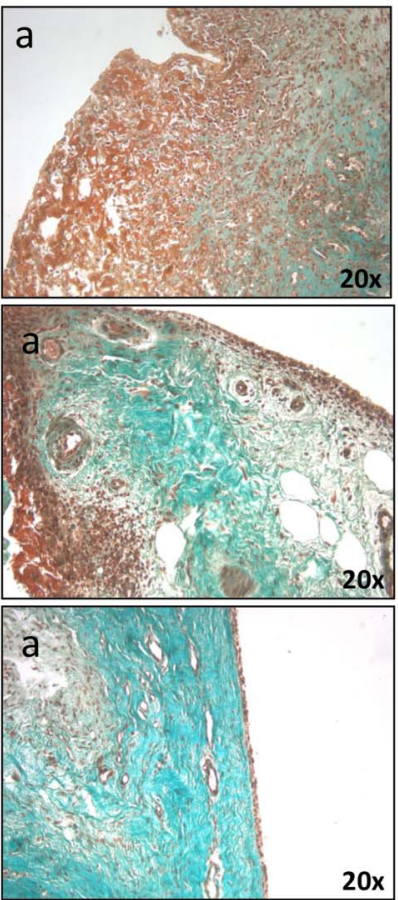
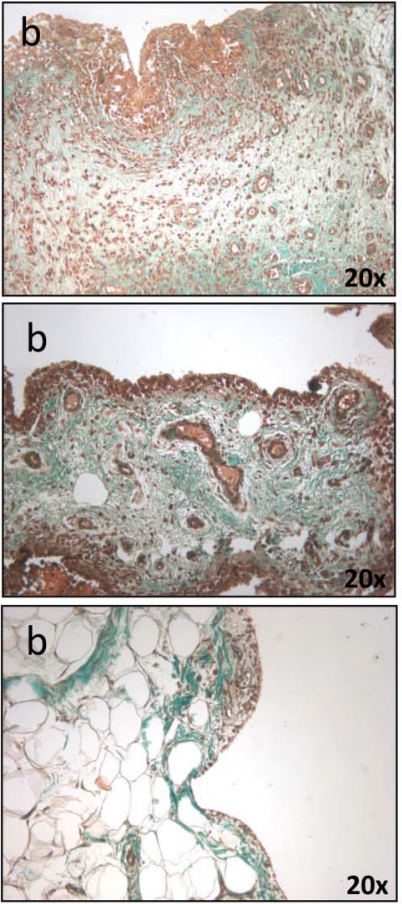
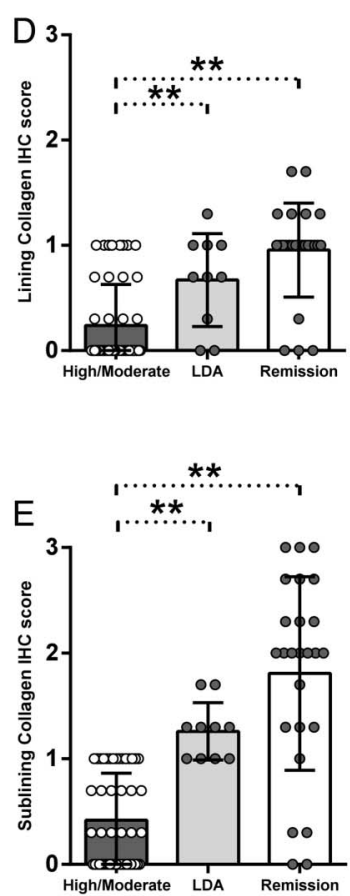

Figure 3 (A-E) Masson Trichrome Goldner with light green immunostaining on ST of patients with rheumatoid arthritis (RA) in remission, in low disease activity (LDA) and in high/moderate disease. (A) Example photos of collagen (green) staining of ST from high/moderate patient with RA $(\mathrm{a}, \mathrm{b})$ (magnification 20x); corresponding ultrasound assessment (US) picture with PD scale (PD score=2) of the knee used for ST biopsy is shown. (B) Example photos of collagen (green) staining of ST from patient with RA in LDA $(a, b)$ (magnification 20x); corresponding US picture with PD scale (PD score=0) of the knee used for ST biopsy is shown. (C) Example photos of collagen (green) staining of ST from patient with RA in remission $(a, b)$ (magnification 20x); corresponding US picture with PD scale (PD score $=0$ ) of the knee used for ST biopsy is shown. (D) Lining IHC score for collagen in ST of enrolled cohorts; high/moderate versus LDA patients with RA, $p=0.03$; LDA versus remission patients with $R A, p=0.10$; high/ moderate versus remission patients with $R A, p<0.001$. (E) Sublining IHC score for collagen in ST of enrolled cohorts; high/moderate versus LDA patients with $R A,{ }^{* *} p<0.001$; LDA versus remission patients with $R A, p=0.10$; high/moderate versus remission patients with $R A$, ${ }^{* *} p<0.001$.

showed higher histological scores for sublining $\mathrm{CD}^{+} 8^{+}$cells $(\mathrm{p}=0.02)$, sublining $\mathrm{CD} 3^{+}$cells $(\mathrm{p}=0.04)$ and $\mathrm{CD} 31^{+}$vessels $(\mathrm{p}<0.001)$ compared with PDUS-negative patients with RA in remission (figure 4C-I). Finally, in PDUS-negative patients with PsA in remission, there was a direct correlation between the histological scores of sublining $\mathrm{CD}^{+}$cells and sublining $\mathrm{CD}^{+} 8^{+}$cells $(\mathrm{r}=0.86 ; \mathrm{p}=0.02)$.

\section{DISCUSSION}

This study shows that PDUS-negative patients with RA in stable remission and in LDA were characterised by similar degree of histologically proven residual synovitis compared with treatment-naïve patients with RA with high/moderate disease activity and that PDUS-negative patients with RA and PsA in stable clinical remission differed at the synovial tissue level in terms of resident inflammatory cells and angiogenesis after TNF inhibitors treatment.

Disease remission achievement is the most important goal in RA treatment, and to date, evidence suggests that while TNF blockers can be discontinued for some patients that have been treated early in their disease course, ${ }^{11}$ stopping anti-TNF in patients with RA with established disease leads to variable rates of disease relapse. ${ }^{12}$ Based on that, it has been suggested that in patients with RA with established disease, dose reduction may be a more realistic approach and can be considered for patients in remission or LDA, either by increasing the interval between doses or reducing the dose administered. ${ }^{13} 14$

Clinical measures of disease remission alone, such as DAS assessment, may underestimate the degree of synovitis, and the systematic use of US is not justified in the follow-up of early patients with RA. ${ }^{15}$ The combined use of US assessment in longstanding patients with RA in clinical remission might increase the success rate after anti-TNF tapering and discontinuation compared with only DAS-based selection. ${ }^{3} 1617$ It has been demonstrated that ongoing synovitis can be detected by US in up to $62 \%$ of patients with RA in clinical remission ${ }^{18-21}$ and that PDUS-detected synovitis correlates with both progression of structural damage ${ }^{22}$ and risk of subsequent RA flare. ${ }^{2}$ However, it is still unclear if this approach could lead to better selection of patients with PsA achieving MDA status by anti-TNF treatment for treatment tapering or discontinuation.

To date, there is no study on the synovial features of patients with RA in clinical remission with PDUS-negative residual synovitis, since limited data are available on the histological composition only of synovial tissue of patients with RA with stable remission, with US-detected synovitis. ${ }^{4}$ Previous studies have focused on the assessment of PDUS-positive residual synovitis in patients with RA with stable remission including heterogeneous RA cohorts, mainly in terms of therapeutic regimen (ie, conventional and biological DMARDs). This may represent an important confounding factor influencing the rate of synovial inflammatory cells whose survival may be differentially affected by pharmacological therapy. To overcome this, at study entry, we performed synovial tissue biopsy of patients with RA in stable clinical and PDUS remission or LDA that were achieved by combination therapy of methotrexate and TNF blockers, the latter used as the first and only biological agent in the patients' disease history. 

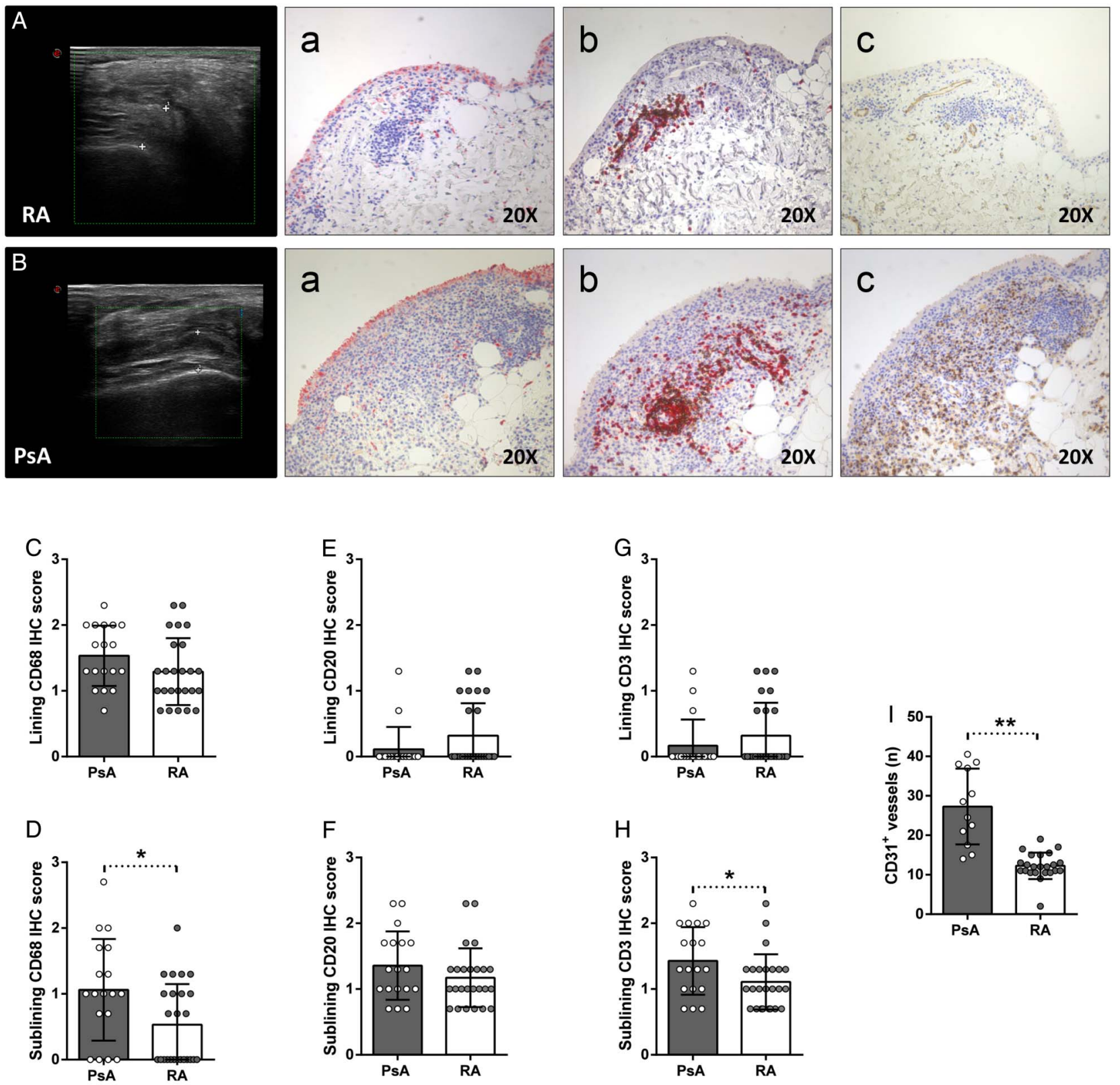

Figure 4 (A-I) IHC staining for CD68/CD21, CD3/CD20 and CD31 on ST of power Doppler (PDUS)-negative patients with rheumatoid arthritis (RA) and psoriatic arthritis (PsA) in disease remission. (A) Example photos of CD68 (red)/CD21 (brown) ( $\left.A^{a}\right)$, CD3 (red)/CD20 (brown) ( $\left.A^{b}\right)$ and CD31 (brown) (AC) staining of ST biopsies from patients with RA in remission (magnification 20x); corresponding ultrasound assessment (US) picture with PD scale (PD score=0) of the knee used for ST biopsy is shown. (B) Example photos of CD68 (red)/CD21 (brown) $\left(B^{a}\right), C D 3$ (red)/CD20 (brown) ( $\left.B^{b}\right)$ and CD31 (brown) (BC) staining of ST biopsies from patients with PsA in remission (magnification 20x); corresponding US picture with PD scale (PD score $=0$ ) of the knee used for ST biopsy is shown. (C) Lining IHC score for $\mathrm{CD} 68^{+}$cells; patients with PsA versus RA, $p=0.12$. (D) Sublining IHC score for $C D 68^{+}$cells; patients with PsA versus RA, * $p=0.02$. (E) Lining IHC score for $C D 20^{+}$cells; patients with PsA versus RA, $p=0.13$. (F) Sublining IHC score for $C D 20^{+}$cells; patients with PsA versus $R A, p=0.22$. (G) Lining IHC score for $C D 3^{+}$cells; patients with PsA versus $R A, p=0.29$. (H) Sublining IHC score for $\mathrm{CD}^{+}$cells; patients with PsA versus RA, ${ }^{p} p=0.04$. (I) IHC score for $C D 31^{+}$vessels; patients with PsA versus $R A,{ }^{* *} p<0.001$.

In the present study, using a combination of clinical and US criteria in patients with long-standing RA, we have shown that both patients with RA in remission and LDA showed less degree of residual synovitis compared with patients with RA with high/ moderate disease activity. In particular, we found significant higher frequency for the presence of follicular synovitis in the latter compared with patients with RA in remission or in LDA. Interestingly, synovial follicles, if present in PDUS-negative patients with RA in remission or LDA, were not homing CD21 ${ }^{+}$ follicular dendritic cells. Moreover, patients with RA in remission and LDA showed comparable degree of residual synovitis with no significant differences in terms of resident $\mathrm{CD} 68^{+}$, $\mathrm{CD} 21^{+}, \mathrm{CD} 20^{+}$and $\mathrm{CD} 3^{+}$cells.

In our study, we found that, if PD signal is absent at the time of disease remission or LDA achievement, it is very likely that synovial tissue is similar between RA in remission and LDA in terms of $\mathrm{CD}_{6} 8^{+}, \mathrm{CD} 21^{+} \mathrm{CD} 20^{+}, \mathrm{CD}^{+}$and $\mathrm{CD} 31^{+}$cells. Ramirez et al demonstrated that despite DAS-based remission reached through various conventional and biological DMARDs, patients with RA with PDUS-positive synovitis show a specific biological profile characterised by an excess of angiogenic mediators compared with patients with RA with PDUS-negative 
remission, ${ }^{20}$ suggesting that the remaining synovial vascularity at local joints may increase the risk of structural deterioration, despite the anti-inflammatory therapy effect. ${ }^{23}{ }^{24}$ These findings confirm that remission in RA requires an improvement of overall disease activity and disappearance of local synovial vascularity detected by PDUS.

In addition, in our study, we reported for the first time the histological features of synovial tissue from PDUS-negative patients with PsA in stable remission (defined using an RA-specific composite index as DAS) and MDA reached under anti-TNF treatment. So far, formal criteria for remission of patients with PsA have not been defined, whereas a state of MDA has been proposed. ${ }^{7}$ Araujo et $a l^{25}$ recently demonstrated that patients with PsA in stable clinical remission (defined as having documented absence of clinical symptoms related to arthritis, dactylitis, enthesitis and axial disease and minimal skin disease with $\mathrm{PASI}<1$ ) have a high chance of disease relapse after treatment discontinuation, suggesting that patients with PsA may be characterised by residual active synovitis. Moreover, the authors suggested that the affected joints in patients with PsA may repeatedly and effectively home inflammatory cells leading to a memory function of the tissue, as the recurrence of the disease usually occurs at the joints which were previously affected by the disease. In our study, we performed synovial tissue biopsy of the knee which was affected during the disease course, showing that patients with PsA in remission are characterised by a higher degree of residual synovitis in terms of $\mathrm{CD}_{6}{ }^{+}, \mathrm{CD}^{+}{ }^{+}$and $\mathrm{CD} 31^{+}$cells, mainly in the sublining, compared with patients with RA in clinical remission despite stable PDUS negativity, providing a biological support to the high rate of disease relapse of patients with PsA after treatment discontinuation. ${ }^{25}$ However, the analysis of the distribution of other resident inflammatory cells, such as mast cells, demonstrated not to be affected by TNF inhibition at synovial tissue level in spondylarthritis, ${ }^{26}$ could provide additional information on the cellular composition of residual synovitis of patients with PsA in MDA under TNF blockage.

In conclusion, the results of our study may have relevant implications to better identify patients with RA in stable clinical remission that could more safely undergo treatment reduction or discontinuation using combined clinical and US selection criteria. Moreover, since patients with RA with long-standing disease reaching LDA status with PDUS-negative tissue have comparable synovial characteristics than patients with RA in remission, tapering anti-TNF agent could be a reasonable choice for clinicians in such patients. However, to definitely confirm the prognostic power of residual inflammatory cells in the synovial tissue of patients with RA or PsA in remission in foreseeing disease relapse, prospective studies performing treatment tapering or discontinuation, based on the combination of clinical, US and histological selection criteria, are needed.

Contributors $\mathrm{SA}$, GF and $\mathrm{EG}$ gave substantial contributions to study conception and design; SA, BT, LP, LB, GDS, RB, GP, ALF and FF gave substantial contributions to acquisition of data; $S A, B T$ GF and $E G$ gave substantial contributions to analysis and interpretation of data; $S A, B T, L P, L B, G D S, R B, G P, A L F, F F$, GF and EG drafted the article and revised it critically for important intellectual content; $S A, B T, L P, L B$, $G D S, R B, G P, A L F, F F, G F$ and $E G$ gave final approval for the version of the article to be published.

Competing interests None declared.

Patient consent Obtained.

Ethics approval Fondazione Policlinico Universitario A. Gemelli-Catholic University of the Sacred Heart Ethical Committee.

Provenance and peer review Not commissioned; externally peer reviewed.
Open Access This is an Open Access article distributed in accordance with the Creative Commons Attribution Non Commercial (CC BY-NC 4.0) license, which permits others to distribute, remix, adapt, build upon this work non-commercially, and license their derivative works on different terms, provided the original work is properly cited and the use is non-commercial. See: http://creativecommons.org/ licenses/by-nc/4.0/

\section{REFERENCES}

1 Yoshimi R, Hama M, Takase K, et al. Ultrasonography is a potent tool for the prediction of progressive joint destruction during clinical remission of rheumatoid arthritis. Mod Rheum 2013;23:456-65.

2 Peluso G, Michelutti A, Bosello SL, et al. Clinical and ultrasonographic remission determines different chances of relapse in early and long standing rheumatoid arthritis. Ann Rheum Dis 2011;70:172-5.

3 Alivernini S, Peluso G, Fedele AL, et al. Tapering and discontinuation of TNF- $\alpha$ blockers without disease relapse using ultrasonography as a tool to identify patients with rheumatoid arthritis in clinical and histological remission. Arthritis Res Ther 2016;18:39.

4 Ramírez J, Celis R, Usategui A, et al. Immunopathologic characterization of ultrasound-defined synovitis in rheumatoid arthritis patients in clinical remission. Arthritis Res Ther 2016;18:74.

5 Aletaha D, Neogi T, Silman AJ, et al. 2010 rheumatoid arthritis classification criteria: an American College of Rheumatology/European League Against Rheumatism collaborative initiative. Ann Rheum Dis 2010;69:1580-8.

6 Taylor W, Gladman D, Helliwell P, et al. Classification criteria for psoriatic arthritis: development of new criteria from a large international study. Arthritis Rheum 2006;54:2665-73.

7 Coates LC, Fransen J, Helliwell PS. Defining minimal disease activity in psoriatic arthritis: a proposed objective target for treatment. Ann Rheum Dis 2010;69:48-53

8 Van de Sande MG, Gerlag DM, Lodde BM, et al. Evaluating anti-rheumatic treatments using synovial biopsy: a recommendation for standardization to be used in clinical trials. Ann Rheum Dis 2011:70:423-7.

9 Bancroft JD, Stevens A. Theory and practice of histological techniques. 4th edn. New York: Churchill Livingstone, 1996.

10 Kurowska-Stolarska M, Alivernini S, Ballantine LE, et al. MicroRNA-155 as a proinflammatory regulator in clinical and experimental arthritis. Proc Natl Acad Sci USA 2011;108:11193-8.

11 Quinn MA, Conaghan PG, O'Connor PJ, et al. Very early treatment with infliximab in addition to methotrexate in early, poor-prognosis rheumatoid arthritis reduces magnetic resonance imaging evidence of synovitis and damage, with sustained benefit after infliximab withdrawal: results from a twelve-month randomized, double-blind, placebo-controlled trial. Arthritis Rheum 2005;52:27-35.

12 Smolen JS, Nash P, Durez P, et al. Maintenance, reduction, or withdrawal of etanercept after treatment with etanercept and methotrexate in patients with moderate rheumatoid arthritis (PRESERVE): a randomised controlled trial. Lancet 2013;381:918-29.

13 Smolen JS, Landewé R, Breedveld FC, et al. EULAR recommendations for the management of rheumatoid arthritis with synthetic and biological disease-modifying antirheumatic drugs: 2013 update. Ann Rheum Dis 2014;73:492-509.

14 Rudolf MD, Deighton C, Bosworth A, et al. Rheumatoid arthritis: national clinical guideline for management and treatment in adults. NICE Clinical Guidelines. London: Royal College of Physicians, 2009. http://www.nice.org.uk/nicemedia/pdf/ CG79FullGuideline.pdf

15 Haavardsholm EA, Aga $A B$, Olsen IC, et al. Ultrasound in management of rheumatoid arthritis: ARCTIC randomised controlled strategy trial. BMJ 2016;354 i4205.

16 Colebatch AN, Edwards CJ, Østergaard M, et al. EULAR recommendations for the use of imaging of the joints in the clinical management of rheumatoid arthritis. Ann Rheum Dis 2013;72:804-14.

17 Navarro-Millán I, Sattui SE, Curtis JR. Systematic review of tumor necrosis factor inhibitor discontinuation studies in rheumatoid arthritis. Clin Ther 2013:35:1850-61.

18 Saleem B, Brown AK, Keen $\mathrm{H}$, et al. Should imaging be a component of rheumatoid arthritis remission criteria? A comparison between traditional and modified composite remission scores and imaging assessments. Ann Rheum Dis 2011;70:792-8

19 Ozgocmen S, Ozdemir H, Kiris A, et al. Clinical evaluation and power Dopple sonography in rheumatoid arthritis: evidence for ongoing synovial inflammation in clinical remission. South Med J 2008;101:240-5.

20 Brown AK, Quinn MA, Karim Z, et al. Presence of significant synovitis in rheumatoid arthritis patients with disease-modifying antirheumatic drug-induced clinical remission: evidence from an imaging study may explain structural progression. Arthritis Rheum 2006:54:3761-73.

21 Ramírez J, Ruíz-Esquide V, Pomés I, et al. Patients with rheumatoid arthritis in clinical remission and ultrasound-defined active synovitis exhibit higher disease 


\section{Clinical and epidemiological research}

activity and increased serum levels of angiogenic biomarkers. Arthritis Res Ther 2014;16:R5.

22 Dougados M, Devauchelle-Pensec V, Ferlet JF, et al. The ability of synovitis to predict structural damage in rheumatoid arthritis: a comparative study between clinical examination and ultrasound. Ann Rheum Dis 2013;72:665-71.

23 Fukae J, Kon $Y$, Henmi $M$, et al. Change of synovial vascularity in a single finger joint assessed by power Doppler sonography correlated with radiographic change in rheumatoid arthritis: comparative study of a novel quantitative score with a semiquantitative score. Arthritis Care Res 2010;62:657-63.
24 Fukae J, Isobe M, Kitano A, et al. Radiographic prognosis of finger joint damage predicted by early alteration in synovial vascularity in patients with rheumatoid arthritis: potential utility of power Doppler sonography in clinical practice. Arthritis Care Res 2011;63:1247-53.

25 Araujo EG, Finzel $S$, Englbrecht $M$, et al. High incidence of disease recurrence after discontinuation of disease-modifying antirheumatic drug treatment in patients with psoriatic arthritis in remission. Ann Rheum Dis 2015;74:655-60.

26 Noordenbos T, Yeremenko N, Gofita I, et al. Interleukin-17-positive mast cells contribute to synovial inflammation in spondylarthritis. Arthritis Rheum 2012;64:99-109. 